\title{
An evaluation of the effect of future climate on runoff in the Dongjiang River basin, South China
}

\author{
KAIRONG LIN, WENLIANG ZHAI, SHUXIAN HUANG \& ZUFA LIU \\ Department of Water Resources and Environment, Sun Yat-Sen University, Guangzhou, Guangdong Province, 510275, \\ China \\ $\underline{\text { linkr@mail.sysu.edu.cn }}$
}

\begin{abstract}
The impact of future climate change on the runoff for the Dongjiang River basin, South China, has been investigated with the Soil and Water Assessment Tool (SWAT). First, the SWAT model was applied in the three sub-basins of the Dongjiang River basin, and calibrated for the period of 1970-1975, and validated for the period of 1976-1985. Then the hydrological response under climate change and land use scenario in the next 40 years (2011-2050) was studied. The future weather data was generated by using the weather generators of SWAT, based on the trend of the observed data series (1966-2005). The results showed that under the future climate change and LUCC scenario, the annual runoff of the three sub-basins all decreased. Its impacts on annual runoff were $-6.87 \%,-6.54 \%$, and $-18.16 \%$ for the Shuntian, Lantang, and Yuecheng sub-basins respectively, compared with the baseline period 1966-2005. The results of this study could be a reference for regional water resources management since Dongjiang River provides crucial water supplies to Guangdong Province and the District of Hong Kong in China.
\end{abstract}

Key words climate change; LUCC, runoff; SWAT; Dongjiang River basin

\section{INTRODUCTION}

Traditional water resources research focuses on the natural hydrological processes, but in recent decades, the hydrological cycle and water security issues under the changing environment have attracted more and more attention. Changing environment, including climate change and human activities, can greatly influence changes of runoff in the basin, which affect and constrain development and utilization of water resources.

Almost all regions of the world will be affected by a net negative impact of climate change on water resources and freshwater ecosystems (IPCC 2007). The potential effects on water resources caused by global climate change in the past few decades have been confirmed by the observation data, simulation research and realistic experience, and hence are of considerable concern (Githui et al. 2009). Climate change will alter snow accumulation and melt and lead to large seasonal changes in runoff and water levels (Veijalainen et al. 2010). The SWAT model can be applied to simulate water quantity and quality and evaluate the effects of land-use change and human activities for sustainable water resource management (Ghaffari et al. 2010). This study derives from a desire to analyse hydrological response to future climate against land-use scenarios. A component of SWAT, the WXGEN model, which can both supplement the missing data and generate climate data was applied to simulate the future climate in the period of 2011-2050.

This paper was organized as the follows: Section 2 briefly introduces methodologies including the SWAT model description and assessment criteria; in Section 3, we describe the study area, data collection and related hydrological data used in this study; Section 4 is devoted to analyses of hydrological response to future climate against land-use scenarios. The last section contains the major conclusions.

\section{METHODOLOGY}

\section{SWAT model description}

The SWAT model developed at USDA-ARS (Arnold and Allen, 1998) has a modelling experience that spans approximately 30 years. The model is semi-distributed, physically-based and can predict the impact of land-use change and management practices on hydrological regimes in watersheds with a variety of soil, land cover and management conditions during the long-term period. The detail and comprehensive descriptions of SWAT were given by Krysanova and Arnold (2008). 
A SWAT interface compatible with GIS software (ArcSWAT) that uses a geo-database approach and a programming structure consistent with the component object model protocol has recently been developed. In SWAT2009, the impacts of spatial variations on topography, land use, soil, and other watershed characteristics related to hydrology are considered in the subdivisions. The SWAT model has been widely used to predict water quantity and quality under varying land use and water use regimes (Muttiah and Wurbs, 2002). This model has also been applied to study potential climate change impacts on water resources (Gosain et al., 2006).

\section{Assessment criteria}

To assess the model performance, the following three objective functions are adopted. The first is to compute the relative error $(\mathrm{Re})$ for measuring the average difference between observations and model simulations of variable $Y$. If the simulation perfectly matches the observation, Re is 0.0 . Positive or negative value indicates over- or under-prediction, respectively.

$$
\operatorname{Re}=\left(\frac{1}{n} \sum_{i=1}^{n}\left(\frac{Y_{\text {sim }}(i)-Y_{\text {obs }}(i)}{Y_{\text {obs }}(i)}\right)\right) \times 100
$$

where $n$ is the sample size, and subscripts $o b s$ and sim refer to the observation and simulation, respectively.

The second one is the Nash-Sutcliffe efficiency (NSE) (Nash and Sutcliffe, 1970), which measures the goodness of fit. NSE is unity if the simulation is perfect. If the efficiency is negative, model prediction is worse than a prediction performed using the average of all observations.

$$
N S E=1-\frac{\sum_{i=1}^{n}\left(Y_{\text {sim }}(i)-Y_{\text {obs }}(i)\right)^{2}}{\sum_{i=1}^{n}\left(Y_{\text {obs }}(i)-\bar{Y}_{\text {obs }}\right)^{2}}
$$

The third is $\mathrm{R}^{2}$ to evaluate the match of variations between observations and simulations. The difference between NSE and $\mathrm{R}^{2}$ is that NSE can interpret model performance in replicating individually observed values while $\mathrm{R}^{2}$ does not (Green and van Griensven, 2008).

$$
R^{2}=\frac{\left(\sum_{i=1}^{n}\left(Y_{\text {obs }}(i)-\overline{Y_{o b s}}\right)\left(Y_{\text {sim }}(i)-\overline{Y_{\text {sim }}}\right)\right)^{2}}{\sum_{i=1}^{n}\left(Y_{\text {obs }}(i)-\overline{Y_{o b s}}\right)^{2} \sum_{i=1}^{n}\left(Y_{\text {sim }}(i)-\overline{Y_{\text {sim }}}\right)^{2}}
$$

\section{REGIONS AND DATA}

\section{Study area}

The Dongjiang River is one of three main tributaries of the Pearl River, which is the fourth largest river in China. The watershed of the Dongjiang River lies between latitudes $22^{\circ} 34^{\prime}$ and $25^{\circ} 12^{\prime} \mathrm{N}$ and longitudes $113^{\circ} 24^{\prime}$ and $115^{\circ} 53^{\prime} \mathrm{E}$. Originating in the Xunwu county of Jiangxi Province, the Dongjiang River flows from northeast to southwest and discharges into the Pearl River delta with an average gradient of $0.39 \%$. The average annual total precipitation is around $1800 \mathrm{~mm}$, and the temporal distribution of rainfall in the watershed is mainly controlled by the monsoon cycle. Shuntian, Yuecheng and Lantang, the three small sub-basins of Dongjiang basin were selected as the research object. The locations of these three sub-basins are shown in Fig. 1.

\section{Datasets}

The ArcSWAT 2009 version has been used for simulations in the present study. The spatial input data layers required to run the model, include a digital elevation model (DEM), land-use data, soil data and weather data. A $30 \mathrm{~m} \times 30 \mathrm{~m}$ DEM obtained from CGIAR-CSI has been used to delineate the boundary of the watershed and analyse the drainage patterns of the terrain. Terrain parameters 


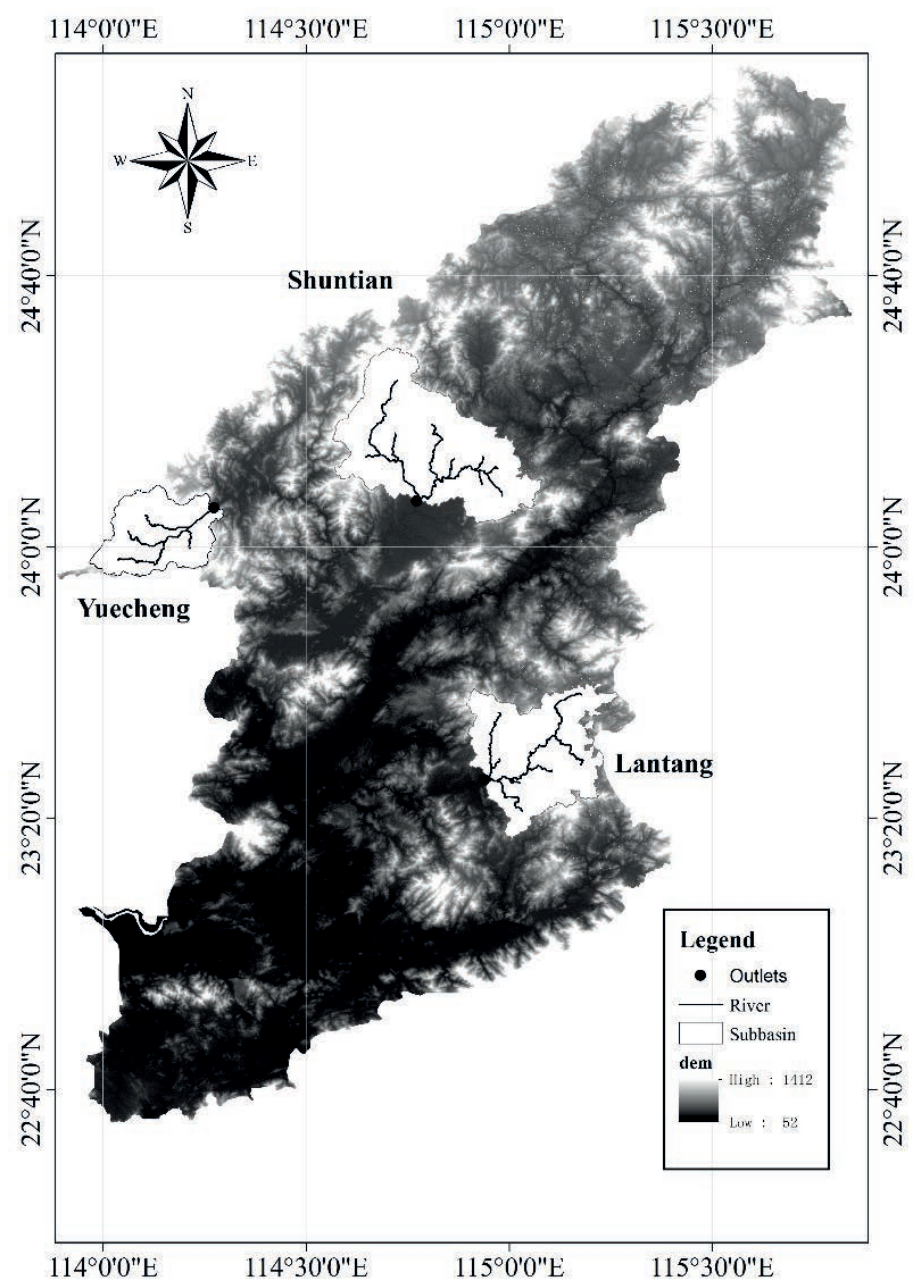

Fig. 1 The distribution of three objective basins in Dongjiang River basin.

such as slope gradient and slope length, and stream network characteristics such as channel slope, length and width, have been derived From DEM. Two land-use maps of the study area were obtained from two multi-temporal satellite sensor images, Landsat Thematic Mapper (TM) imagery of the 1980s and 2000s, which were downloaded from the Global Land Cover Facility National Remote Sensing Centre (NRSC), Government of India (GOI). The 1980s land-use map represents the natural scenario that is not affected by human activities, while that of $2000 \mathrm{~s}$ is representative of urbanization. The NRSC land-use data contain crop-specific digital layers, suitable for use in a Geographic Information System (GIS). The soil data were obtained from the China Soil Scientific Database (CSSD). Requisite weather data were obtained from the three meteorological stations of Shenzhen, Huiyang and Dongguan for a period of 53 years (1953 to 2005) and incorporated in the model; they include daily temperature, precipitation, wind speed, relative humidity and so on. Hydrologic data mainly including 36 years (1970-2005) monthly series runoff and two periods of daily precipitation data (1970-1985 and 1996-2005) at Shuntian, Yuecheng and Lantang hydrologic stations were used in this study.

\section{Calibration and validation}

The SWAT model was first calibrated by a manual calibration method during the baseline period of 1970-1975 at Shuntian, Yuecheng and Lantang stations, and validated by using the period of 1976-1985 at these three stations (Lin et al., 2013). Both processes were carried out at monthly time steps as a result of long period objective climate change. This was easily linked to SWATCUP through an interface, which can be downloaded from the SWAT website. 
Based on analysis of parameter sensitivity and taking previous studies into account (Wang et al., 2003), eight key parameters were identified for model calibration and validation. Compared to others' research (Wu and Chen, 2013), the results were acceptable. The value of the assessment criteria are shown in Table 1. For the calibration period, the Nash-Sutcliffe coefficient of efficiency values (NSE) (Nash and Sutcliffe 1970) were all greater than $80 \%$, the coefficient of determination $\left(\mathrm{R}^{2}\right)$ were all greater than $85 \%$, and the relative error $(\mathrm{Re})$ were all smaller than $9 \%$ for the three stations at monthly scale. For the validation period, all the three basins have satisfying NSE, Re and $\mathrm{R}^{2}$ values. It was shown that SWAT fitted well in the Dongjiang River basin and can be applied to project future climate and simulate corresponding runoff.

Table 1 The results of calibration and validation in three basins.

\begin{tabular}{llllllllll}
\hline Period & \multicolumn{2}{l}{ Shuntian } & \multicolumn{3}{c}{ Yuecheng } & \multicolumn{3}{c}{ Lantang } \\
& $\operatorname{Re} / \%$ & $R^{2} / \%$ & $N S E / \%$ & $\operatorname{Re} / \%$ & $R^{2} / \%$ & $N S E / \%$ & $\operatorname{Re} / \%$ & $R^{2} / \%$ & $N S E / \%$ \\
\hline $1970-1975$ & 7.8 & 94.8 & 91.6 & 5.4 & 91.8 & 89.9 & 4.2 & 86.6 & 84.0 \\
$1976-1985$ & 2.5 & 92.9 & 91.6 & 6 & 94.9 & 94.3 & -5 & 89.9 & 87.1 \\
\hline
\end{tabular}

\section{GENERATE FUTURE CLIMATE DATA}

Based on the baseline period (1966-2005) meteorological data, a very thorough analysis of the temperature and precipitation variables was done by Kendall statistics. The Kendall statistic of annual average temperature was 5.54 and passed the test of significance of $99 \%$ confidence level, which proved that there was an obvious warming up tendency at all the three basins. Analogously, all 12 monthly-average temperatures had a temperature rise trend. In contrast, the three basins have different precipitation characteristics but all have a non-significant declining trend according to the Kendall statistics.

The future climate data (2011-2050) was generated with the WXGEN model by inputting preexisting meteorological data, mainly temperature and precipitation, and their trend on the basis of the calibrated SWAT model.

\section{HYDROLOGICAL RESPONSE OF RUNOFF TO FUTURE CLIMATE}

\section{Land-use scenario}

It is hard to predict the development of land use because too many factors need to be considered and their contributions to promoting urbanization are elusory. So the land-use map of the $2000 \mathrm{~s}$ was still employed in this study. The detailed information of the land-use scenario are shown in Table 2.

Table 2 The detailed information of the land-use scenario.

\begin{tabular}{lccc}
\hline Land-use type & Shuntian basin & Yuecheng basin & Lantang basin \\
\hline AGRL (\%) & 36.78 & 6.78 & 15.67 \\
ORCD (\%) & 1.98 & 1.34 & 4.93 \\
FRST (\%) & 58.69 & 70.04 & 73.94 \\
PAST (\%) & 2.38 & 20.2 & 4.34 \\
URHD (\%) & 0.18 & 0 & 1.11 \\
WATR (\%) & 0 & 1.64 & 0 \\
\hline
\end{tabular}

\section{Change of annual runoff}

Compared to the baseline period observed runoff, there were declines of $6.87 \%, 6.54 \%$ and $18.16 \%$ in annual runoff in Shuntian, Yuecheng and Lantang basins, respectively, under the future climate change and land-use scenario. The details are listed in Table 3. Regarding Shuntian basin, there were $7.44 \%, 11.47 \%, 2.46 \%$ declines in spring, summer and autumn, respectively, while 
there was a $14.1 \%$ increase of future runoff in winter. Relatively little precipitation impacts on runoff in Yuecheng basin; there were $12.98 \%, 10.81 \%, 4.93 \%$ declines in spring, summer and winter, and a $3.21 \%$ increase in autumn. The greatest change occurred in Lantang basin where there were declines of $7.78 \%, 22.94 \%, 30.07 \%$ and $9.02 \%$ in spring, summer, autumn and winter, respectively, which corresponds to the change of future precipitation. Overall, in summer a bigger percentage decline in runoff revealed that runoff reduced much in the early flood season, which could lead to lack of water or even droughts. Due to a more or less decline in Yuecheng and Lantang basins both in winter and spring, i.e. in the non-flood season, shortages of water volume would be worse and become a challenge to industrial consumption and domestic water supply. In contrast, the situation in Shuntian basin took a turn for the better because of a bigger increase in winter.

Table 3 The percentage of change of runoff compared to baseline period.

\begin{tabular}{lrrrrrr}
\hline Basin & \multicolumn{2}{c}{ Runoff change (\%) } & & \multicolumn{2}{c}{ Mean annual runoff $(\mathrm{mm})$} \\
& Spring & Summer & \multicolumn{1}{c}{ Autumn } & \multicolumn{1}{c}{ Winter } & \multicolumn{1}{l}{ Year } & \\
\hline Shuntian & $-7.44 \%$ & $-11.47 \%$ & $-2.46 \%$ & $4.10 \%$ & $-6.87 \%$ & 961.19 \\
Yuecheng & $-12.98 \%$ & $-10.81 \%$ & $3.21 \%$ & $-4.93 \%$ & $-6.54 \%$ & 1115.48 \\
Lantang & $-7.78 \%$ & $-22.94 \%$ & $-30.07 \%$ & $-9.02 \%$ & $-18.16 \%$ & 793.14 \\
\hline
\end{tabular}

\section{The CV of runoff}

Based on the future climate and baseline land use, the coefficient of variation (CV) of seasonal runoff and annual runoff were analysed and listed in Table 4. It can be seen that the values of CV of the future period were smaller than of the baseline period, not only for the annual projections one but also for seasonal ones. Namely the variation of runoff would reduce, especially in spring and winter. All the values of CV were smaller than 0.4 in all the three basins, and especially smaller than 0.3 in Yuecheng basin. The smaller CVs indicated that the difference of runoff among years at the same season was smaller, which would be good for water management.

Table 4 The CV of runoff during the baseline period and future period.

\begin{tabular}{lllllll}
\hline Basin & Scenario & CV & & & & \\
& & Spring & Summer & Autumn & Winter & Year \\
\hline Shuntian & Baseline period & 0.552 & 0.465 & 0.454 & 0.847 & 0.333 \\
& Future period & 0.256 & 0.342 & 0.372 & 0.349 & 0.223 \\
Yuecheng & Baseline period & 0.544 & 0.381 & 0.3 & 0.531 & 0.293 \\
& Future period & 0.25 & 0.29 & 0.24 & 0.253 & 0.203 \\
Lantang & Baseline period & 0.663 & 0.373 & 0.552 & 0.553 & 0.324 \\
& Future period & 0.317 & 0.393 & 0.375 & 0.331 & 0.263 \\
\hline
\end{tabular}

\section{CONCLUSIONS}

First, the SWAT model was applied to Shuntian, Yuecheng, and Lantang basins with a calibration period of 1970-1975, and validation period of 1976-1985. In both periods, the Nash-Sutcliffe coefficient of efficiency values (NSE) were greater than $80 \%$, the coefficient of determination $\left(\mathrm{R}^{2}\right)$ were greater than $80 \%$, and the relatively error $(\mathrm{Re})$ were smaller than $9 \%$ for the three basins at monthly scale. This indicated that the SWAT model was suitable for Dongjiang River basin.

Secondly, according to the trend of climate change, meteorological data of three basins in the forecast period (2011-2050) were generated by WXGEN generator and then input to the SWAT model to study the impact of the future climate on runoff in the Dongjiang River basin. The results showed that all the three basins have less mean annual runoff and have smaller CV especially in spring and winter than that of baseline period (1966-2005) under the future climate change and land-use scenario. The results of this study could be a reference for regional water resources 
management since Dongjiang River provides crucial water supplies to Guangdong Province and the District of Hong Kong in China. Further study should be done by inspecting the reliability or uncertainty of the so-called physically-based model structure.

Acknowledgements This study was financially supported by the National Natural Science Foundation of China (Grant 51379223), the Pearl-River-New-Star of Science and Technology supported by Guangzhou City (Grant 2011J2200051).

\section{REFERENCES}

Arnold, J.G. and Allen, P.M. (1998) Large area hydrologic modeling and assessment. Part I: Model development. Journal of the American Water Resources Association 34 (1), 73-89.

Ghaffari, G., et al. (2010) SWAT simulated hydrological impact of landuse change in Zanjanrood basin, Northwest Iran. Hydrological Processes 24(7), 892-903.

Githui, F., et al. (2009) Climate change impact on SWAT simulated streamflow in western Kenya. International Journal of Climatology 29(12), 1823-1834.

Gosain, A.K., Rao, S. and Basuray, D. (2006) Climate changes impact assessment on hydrology of Indian river basins. Current Science 90 (3), 346-353.

Green, C.H. and van Griensven, A. (2008) Auto calibration in hydrologic modeling: using SWAT2005 in small-scale watersheds. Environmental Modelling \& Software 23 (4), 422-434.

IPCC (2007) Climate Change 2007: Climate change impacts, adaptation and vulnerability Summary for Policymakers, Contribution of the Working Group II to the Fourth Assessment Report of the Intergovernmental Panel on Climate Change, Eds., Cambridge University Press, Cambridge, UK, 2007.

Krysanova, V. and Arnold, J.G. (2008) Advances in eco-hydrological modelling with SWAT - a review. Hydrological Sciences Journal 53 (5), 939-947.

Lin, K., et al. (2013) Appliction of SWAT model in Dongjiang River basin. Journal of China Hydrology 33(4), 32-36.

Muttiah, R.S. and Wurbs, R.A. (2002) Scale-dependent soil and climate variability effects on watershed water balance of the SWAT model. Journal of Hydrology 256, 264-285.

Nash, J.E. and Sutcliffe, J.V. (1970) River flow forecasting through conceptual models: 1. A discussion of principles. Journal of Hydrology 10, 282-290.

Veijalainen, N., et al. (2010) Climate change impacts on water resources and lake regulation in the Vuoksi watershed in Finland. Water Resources Management 24(13), 3437-3459.

Wang, G.X., Liu, C.M. and Huang, Y.B. (2003) The theory of SWAT model and its application in Heihe Basin. Progress in Geography 22(1), 79-86.

$\mathrm{Wu}, \mathrm{Y}$. and Chen, J. (2013) Analyzing the water budget and hydrological characteristics and responses to land use in a monsoonal climate river Basin in South China. Environmental Management 51, 1174-1186. 